\title{
A Technique for Mapping Mathematics Content to Game Design
}

\author{
Vani Kalloo ${ }^{1}$, Permanand Mohan ${ }^{2}$ and Kinshuk ${ }^{3}$ \\ 1, 2 Department of Computing and Information Technology \\ The University of the West Indies, Trinidad and Tobago \\ ${ }^{1}$ vani.kalloo@gmail.com \\ ${ }_{2}^{2}$ Permanand.Mohan@sta.uwi.edu \\ ${ }^{3}$ School of Computing and Information Systems \\ Athabasca University, Canada, kinshuk@ieee.org
}

\begin{abstract}
Research has shown that games can be valuable tools for learning mathematics. In this paper, we explain how we tackled the challenge of mapping mathematics content to games in the design of mathematics learning games. We present a unique technique for mapping mathematics content to game design. The technique can be used to improve the game design process by guiding the designer through one of the more challenging stages of the design process, namely, that of incorporating mathematics content into a game. The technique is based on several factors such as mathematics learning pedagogy, game type categorization, the mathematics curriculum, and past research experience. The technique is unique since it focuses on guiding the game designer through the process of mapping the mathematics content to the game idea. Additionally, the technique incorporates several important game design principles. A preliminary evaluation of the technique was conducted with several amateur game designers. Although there are several limitations of the technique, the evaluation shows that it was useful in helping the game designers to design suitable mathematics learning games.
\end{abstract}

Keywords: mathematics, game design, serious games, instructional design, content, pedagogy.

\section{Introduction}

Games by nature facilitate some type of learning, and if suitably designed, can be used for learning mathematics. The player is often learning something, whether it is better hand-to-eye coordination, clever strategizing or history from a game context. Many researchers agree that games can be used for learning [1] [2] [3] [4] [5]. Over the years, games have moved from being thought of as a distraction and a disturbance, to being considered a valuable asset to teaching and learning. Even though several researchers [6] [7] [8] argue that there is a lack of evidence that digital game based learning is effective, there is considerable research which show that games can significantly affect learning outcomes. Games have proven to be suitable for learning many diverse subject areas such as history, English, physics and soft skills such as teamwork. Koster [9] pointed out that the brain is great at recognizing patterns such as the ones presented in games. Salingaros [10] claimed that mathematics is all about patterns. Koster [9] goes on to make the point that this very characteristic of mathematics indicates that there is a strong potential connection between games and mathematics. A basic assumption in this paper is that games can be used for learning mathematics, a belief that is supported by several researchers [11] [12] [13]. Furthermore, we argue that a form of blended learning consisting of learning games and classroom learning can be ideal for learning mathematics.

It is difficult to design successful games especially with the constraint of having to embed learning content directly into the game play. Based on past experiences and the results of studies from other researchers, we hypothesized that learning games should be designed with the learning as a major part of the game play and not as an addition or add-on after the game is designed. Asplin et al. [14] indicated that this latter approach is common since games have widely been used as a time-filler or reward with no attempt at embedding mathematics learning as part of the game play. In order to foster the learning of mathematics as part of the game play, we had to address the challenge of embedding content into the game play and designing the game so that it would appeal, engage, and keep the attention of potential players (learners). This process can be very demanding, time consuming and tedious. Our research 
question was therefore, how to efficiently design games which integrate mathematics directly into the game play?

In this paper, we present a technique for guiding the game designer through the process of mapping mathematics content to the game design when designing mathematics learning games. An evaluation study was conducted where several amateur game designers used the technique. They produced several mathematics learning game designs and provided valuable feedback on the use of the technique. The rest of the paper is organized as follows. Section 2 is a literature review describing other approaches to game design. This is followed by Section 3 which explains how we went about developing our game design technique which embeds mathematics content in the game play. Section 4 discusses how the technique was evaluated. Section 5 describes the contributions of our research as well as the limitations of the technique presented. The paper concludes in Section 6 by summarizing the research presented and highlighting areas for further research.

\section{Related Work}

A study of the literature reveals that there are several approaches to game design. Becker and Parker [15] discussed a few main ones such as Brainstorming, Rapid Iterative Prototyping and Serious Instructional Design Model. Brainstorming is an ideation session in an effort to produce game design ideas. Rapid Iterative Prototyping (RAP) is a process of developing an initial prototype, reviewing, and refining it. Serious Instructional Design Model is a design process which combines game design, simulation design, and instructional design, and blends important elements of each. Rogers [16] suggested some general ideas for game design such as reading something out of the ordinary, playing a game, taking a walk, attending a lecture or brainstorming. Schell [17] presented the idea of lenses, which are multiple perspectives of viewing a game design as part of the game design process. The game designer is encouraged to ask a set of questions about his design as a method of examining and refining his game. These lenses are provided in a set of cards as a tool for the game designer. Salen and Zimmerman [18] offered an approach to game design which is based on playtesting and prototyping. In this approach design decisions are made based on the experience of playing a game while it is being developed. This approach is suitable after the designer has already produced an initial idea for the game; however, the designer is still left with the difficult problem of creating that initial idea.

Many game designers, such as Rogers [16] who has over twenty years' experience in the game industry, agree that it is difficult to design successful games. Furthermore, the added constraint to map mathematics learning into the game increases this difficulty. There have been several attempts at solving this problem. Researchers have tried authoring tools, separation of the content and game creation, and game modding. Torrente et al. [19] suggested the use of instructor-oriented authoring tools which focus on extracting the programming tasks and specifically supports the educational domain. Torrente et al. [19] proposed that this would help address problems such as high costs of development and difficulty in getting educators involved in learning game creation. Abdullah et al. [20] also suggested an authoring tool to encourage teachers to produce game-based educational content in an effort to tackle the problem of games being difficult to build. Gomez-Martin et al. [21] proposed a two-level architecture, where domain experts create exercises and game designers create the game template. This approach is problematic because the separation of the content and the game play leads to the content not being a major part of the game. Fanning [22] and Prensky [23] suggested the use of game modding to be used for making the game creating process easier. Game modding is the adaptation of game content from an already existing commercial video game in order to create a different game. Game modding was expected to provide a way for educators to use quality games and create new learning games for students. However, in cases where it is difficult to get teachers to use basic ICT in their classrooms due to fear of technology, it may be unrealistic to expect them to make use of game modding or authoring tools for creating educational games. This point is supported by Tondeur et al. [24] who, based on a study conducted with 570 participants in Belgium, indicated that teachers seem to embrace ICT but the actual use of it is lacking. Moreno-Ger et al. [25] proposed a general game design method which integrated adaptation and assessment. Their game design method addressed issues such as cost of development, complexity of curriculum integration and the need to assess the quality of the learning. Moreno-Ger et al. [25] proposed a set of design guidelines which can guide a designer to choose a genre, add assessment and adaptation to the design and integrate with an online environment. This method was intended to be used for general game design and it focused on only two criteria which affects learning. Arnab et al. [26] presented some key elements for the design of serious games. They provided a mapping of learning goals to game mechanics. This mapping addresses issues related to effective serious game design and helps the designer determine where game play and pedagogy intertwine. This method can be applied to learning games in general; however, it does not cater for specific and unique subject areas such as mathematics. 
The literature shows that there is still a need for solutions to the problem of integrating mathematics content in the design of mathematics learning games.

\section{Designing Games for Learning Mathematics}

\subsection{Factors which Influenced the Technique}

We developed a technique for designing learning games for mathematics in an effort to improve the game design process. The technique is based on several influencing factors. Salen and Zimmerman [18] presented a collection of principles to consider when designing games such as design, systems, interactivity, player choice, action, rule-making, game experience, emergence and complexity. In our research, we focus on the design of mathematics learning games and four factors were considered in the development of the technique. These factors are game categorization, the mathematics curriculum, instructional design and pedagogy, and past research experience in learning mathematics games. These factors were chosen since they each represent an important aspect of mathematics learning games.

Game categorization is a method of grouping common or reoccurring gaming ideas or concepts. Game categories can encourage the use of common aspects of successful games such as appeal, enjoyment, playability and competition since game categories are extracted from successful games. These categories cannot guarantee success but can help the designer incorporate aspects of successful games. The mathematics curriculum incorporates the mathematics learning aspect of the game designed process. Instructional design and pedagogy is important when designing learning tools where factors such as learnability are integrated. The past research experience of the authors was gained from a previous mobile learning mathematics study which included games. Lessons learned from this study were incorporated into the development of our technique.

Game categorization is one of the influencing factors of the game design technique. There are many common game design concepts or ideas which reoccur among successful game designs and reuse of these is common. Game types and patterns in game design are used for game categorization in our technique. Game types are a way of categorizing common game design characteristics; some examples are puzzle, adventure, role playing and multiplayer games. However, since games are so complex, they can comprise several of these categories or subdivisions of these categories. This can result in an inconsistent categorization where some games are categorized differently by different people. Consequently, patterns in game design were chosen to identify reusable ideas. Patterns in game design [27] are defined as reoccurring design choices in games. They capture the different aspects of each game, making it easier to describe individual games consisting of multiple categories and subdivisions of categories. Some examples of patterns in game design are Race, Power Ups, Survive, Eliminate, Delivery and Last Man Standing. In our research, we decided to use both patterns in game design and game types to describe different games, depending on which is most appropriate. Factors such as engagement, appeal and interactivity in our technique are provided by reusing well-known patterns in game design. Therefore, the use of such patterns increases the chances of success in these games.

The mathematics curriculum is another factor which can significantly influence the development of the game design technique for mathematics learning games. The high school mathematics curriculum was studied to determine how to systematically transform mathematics topics into game ideas. The mathematics learning objectives, common problems, and solutions were investigated for each topic. This investigation led us to recognize that each topic could be categorized into a set of common mathematics objectives. This was done by abstracting the skill from each mathematics topic in an effort to transform the mathematics skill into a game idea. For instance, consider the topic Basic Number Theory, where one of the objectives is to recognize factors. The learner has to learn the definition of a factor and be able to recognize factors as well as derive factors. This led to the first common objective which was called Identification and it refers to the recognition or identification of some predefined criteria. There are several other topics which require the identification of some specific criteria. Identification could be applied to Number Theory, Sets and Factorization. In the Sets topic, the learner needs to identify a set, and in Factorization, he or she is required to identify factors from an expression in order to factorize.

Instructional design and mathematics pedagogy are also significant factors which were studied in the development of our game design technique. These factors are important to ensure that the learning of mathematics within the game has a high chance of being effective. Gagne's learning theory was chosen for this study as Becker [28] was able to apply it to games, showing how good games contain key principles of learning and instructional theories. According to Gagne, learning should be attention gaining, it should inform the learner about the objectives, stimulate recall of prior knowledge, present stimuli, be accompanied by guidance, elicit performance, provide feedback, assess performance, and encourage retention and transfer. Becker [28] pointed out that many of these qualities can be seen in good 
games. We argue that by including of patterns in game design [27], which were extracted from a study of successful games, there is an increased probability that the games designed will be successful. Therefore, new games designed using patterns can incorporate some or all of Gagne's learning principles, increasing the probability of successful learning [29].

Table 1 summarizes a mathematics pedagogy developed by the International Academy of Education based on research evidence produced by the Ministry of Education in New Zealand [30]. The left column of the table briefly outlines the principles of the pedagogy for effective mathematics teaching. The right column describes how our technique has incorporated several of these principles. Some have been incorporated directly into our technique; others have been integrated indirectly through the adoption of patterns in game design and game types.

Another factor which influenced the development of our technique is past research experience. The authors have gained experience in designing and developing mobile games for learning mathematics in a mobile learning study [31]. In this experience, several key factors were identified as essential for creating games for learning mathematics. One key factor is to ensure that the game is based on one small mathematics topic. When each game is based on one small mathematics topic, which is acquired by breaking up a main topic into its smaller topics, it is easier for the player to master that topic and most likely easier for the designer to translate this small topic into a game. Another key factor identified is designing the content to be embedded into the game play. The mathematics content being well-embedded into the game play means that once the player gets caught up in the game play, learning can occur as he or she plays. Becker and Parker [15] argue that designing learning games is much more than just adding content to a game, and that there must be some learning goal in mind. The last key factor learnt is to ensure that the game has features to compel the player to play often and for long periods. The player should see the game as fun and exciting where he or she willingly chooses to play.

Table 1. Incorporating mathematics pedagogy in the technique

Key Points proposed by the pedagogy [30]
An ethic of care - helps the students develop mathematical
identities and proficiencies.

Independent and collaborative - providing students with opportunities to work independently and collaboratively. Building on students' thinking - plan learning experiences that enable the learner to build on existing proficiencies, interest and experiences.

Worthwhile mathematical tasks - the provision of tasks and examples which help students to view, develop, use and make sense out of mathematics.

Making connections - help students make the connections between different solutions, as well as between mathematics and everyday experiences.

Assessment of learning - use a range of assessment practices to make students' thinking visible and to support students' learning.

Mathematical communication - facilitate mathematics communication among students.

Mathematical language - modelling appropriate mathematical terms and communicating their meaning in ways that students understand.

Tools and representations - provides tools and representations for supporting students' thinking.

Teacher knowledge - develop and use sound knowledge as a basis for initiating learning and responding to the

\section{Application of pedagogy to our technique}

When students are given the opportunity to learn mathematics with a game, this can demonstrate to them that their mathematics proficiency is of concern because they are given the opportunity to learn with a preferred [31] and enjoyable activity.

Games are ideal for providing independent and collaborative mathematics learning.

*The patterns in game design offer students a tool of common interest and experience as they are based on proven, popular game concepts, which most game players are familiar with.

*This technique advises the designer to work closely with common problems of the selected topics, providing a game based on the solution steps to worthwhile mathematics problems.

Games, based on how they are designed, have the ability to show connections between real uses of mathematics and the topics taught in the classroom.

*Patterns such as reward, reward/risk and score encourage feedback and assessment. Therefore as the player plays, his knowledge is continually assessed and feedback is provided.

Collaborative mathematics games can establish and encourage communication among players. This can also be facilitated by the use of social media to discuss game play.

*The process of mapping mathematics to a mathematics objective and game category within the technique essentially attempts to translate the mathematics language into a more understandable form for the player to relate to. For example, understanding factorization as extracting something, namely, divisors.

*The tools here are the game designs which are mapped to common mathematics objectives which can be designed to support student thinking. These game designs are the representation of the mathematics concept for the player.

*In this technique, the game designer must have a basic knowledge of mathematics. The content in the games can also 
* The pedagogy is directly applied to the technique

\subsection{Technique for Designing Learning Games for Mathematics}

Given the influencing factors, a technique for designing mathematics learning games was formulated. Figure 1 is a flow chart outlining the technique. In step 1 the designer is guided to choose a mathematics topic, which the game is to be based on. As part of the technique, the game designer is provided with the mathematics curriculum with a detailed breakdown of each topic. It is then suggested that a subtopic be selected so that the game is based on a fragment of the topic. If the game is based on a fragment of the topic (a small topic), it is more likely that the game design process is easier. Additionally, this makes it easier for the learner to comprehend the topic when playing. A subtopic refers to one component of a topic (a small topic) when it is divided into smaller parts.

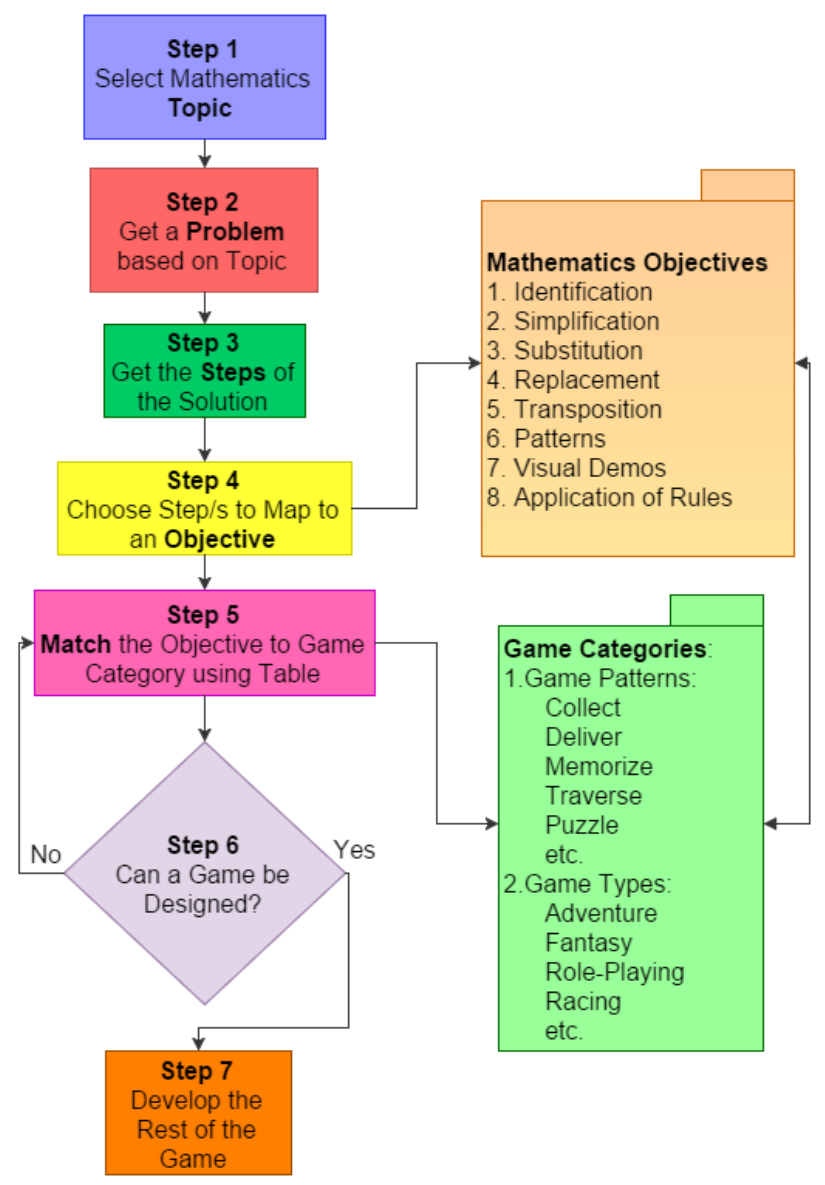

Figure 1. Mathematics game design technique

In step 2, the designer is advised to identify a common problem based on the chosen topic. This information will be provided in the mathematics curriculum. In step 3, it is suggested that the problem be broken down by outlining the solution step by step. This detailed look at the solution gives the designer deeper insight into the learning objectives of the topic. The authors recommend that the games be designed with the intention of helping learners practise mathematics skills, not necessarily teaching them from scratch.

Step 4 of the technique guides the designer to search for one part of the solution which can be mapped to one of the common mathematics objectives which is given in Figure 1. These mathematics objectives were derived from a comprehensive analysis of the mathematics curriculum and are intended as a means of helping the game designer to map the chosen topic to a suitable game design idea. Each mathematics topic was broken down and investigated in search of a core objective that could be extracted. These core objectives were then consolidated where common objectives were recognized. This led to seven core mathematics objective which could cover almost all the mathematics topics of the curriculum. Table 2 
shows these mathematics objectives in more detail. Each mathematics objective is described and matched to suitable game types and patterns in game design. The objectives are Identification, Simplification, Substitution or Replacement, Transposition, Patterns, Visual Demos and Application of Rules. Identification is the recognition of some defined criteria, for example, the identification of common factors, sets, a specified type of angle or triangle etc. Simplification is the reduction of complexity, for example approximation, directed numbers, arithmetic and simplification of algebraic expressions etc. Substitution is the replacement of one element with another which is equivalent, for example, substituting an algebraic letter with a numerical value or substituting numbers into a standard rule such as area or volume of a shape. Transposition is the shifting of terms or operands from one side of an equation to another, for example, when solving an equation, changing the subject of a formula or when solving proofs. Patterns are the reoccurrence of something which can be replicated, for example, sequences, matrix operations, functions and relations etc. Visual demonstrations are used for concepts which are best displayed visually using diagrams or animations such as graphs, trigonometry and transformations. The Application of Rules is the concept of being able to apply rules to actual problems, for example, worded problems.

The designer is urged to select the most suitable part of the solution which can be mapped to one of the given mathematics objectives. Step 5 helps the designer to match the mathematics objective to a pattern in game design or game type. A subset of patterns in game design and game types is shown in Figure 1. In our technique, we use almost 300 patterns in game design and the designer is expected to select one for the game core dynamic (the main idea of the game play [32]); however, many patterns can be used within one game.

Table 2. Mathematics objectives matched to patterns in game design

\begin{tabular}{|c|c|c|c|c|}
\hline & $\begin{array}{l}\text { Mathematics } \\
\text { Objective }\end{array}$ & Description or Example & $\begin{array}{l}\text { Genres or Game Types } \\
\text { which Match the } \\
\text { Objective }\end{array}$ & $\begin{array}{l}\text { Patterns in } \\
\text { Game Design }\end{array}$ \\
\hline 1 & Identification & Identify a defined item. & $\begin{array}{l}\text { Collection, Catch, Shoot, } \\
\text { Search and Find }\end{array}$ & $\begin{array}{l}\text { Aim \& Shoot } \\
\text { Collecting } \\
\text { Capture } \\
\text { Exploration } \\
\text { Pick-Ups }\end{array}$ \\
\hline 2 & Simplification & $\begin{array}{l}\text { Simplify a mathematics } \\
\text { element. }\end{array}$ & Merge, Tile shifting & Merge** \\
\hline 3 & $\begin{array}{l}\text { Substitution/ } \\
\text { Replacement }\end{array}$ & $\begin{array}{l}\text { Replacing an unknown } \\
\text { with its value. }\end{array}$ & Swap. Search and Find & Swap** \\
\hline 4 & Transposition & $\begin{array}{l}\text { Shift operands from one } \\
\text { side of an equation to } \\
\text { another. }\end{array}$ & Balancing & $\begin{array}{l}\text { Delivery } \\
\text { Indirect Control } \\
\text { Moveable Tiles } \\
\text { Movement } \\
\text { Limitations } \\
\text { Outcome } \\
\text { Indicators } \\
\text { Traverse }\end{array}$ \\
\hline 5 & Pattern & $\begin{array}{l}\text { Recognizing a pattern and } \\
\text { being able to replicate it. }\end{array}$ & Puzzles & $\begin{array}{l}\text { Collection } \\
\text { Memorization } \\
\text { Puzzle Solving }\end{array}$ \\
\hline 6 & Visual Demos & $\begin{array}{l}\text { Concepts best shown } \\
\text { visually, e.g., Graphs, Venn } \\
\text { Diagrams. }\end{array}$ & Demo, Animation & $\begin{array}{l}\text { Demo } \\
\text { Animation }\end{array}$ \\
\hline 7 & $\begin{array}{l}\text { Application of } \\
\text { Rule }\end{array}$ & $\begin{array}{l}\text { Identification of rules and } \\
\text { unknowns, substitution and } \\
\text { simplification. }\end{array}$ & Same as 1,2 and 3 above & $\begin{array}{l}\text { Same as } 1,2 \text { and } \\
3 \text { above }\end{array}$ \\
\hline
\end{tabular}

** These are not patterns in game design or game types. These were created to suit the respective matching objective.

At this point, the designer has a game core dynamic [32] to use as inspiration to design a mathematics game based on the given topic. The designer is then encouraged to work with this information, with the intention of coming up with a game design formulated around the given pattern in game design or game type. Step 6 guides the designer on what to do next depending on if a game can be designed or not. If the designer has successfully produced a game design idea, then he or she has to elaborate the rest of the game. Björk and Holopainen [27] presented a framework for describing games which introduce the concepts of the physical and logical components of the game. Our technique suggests the use of this 
game component framework to help the designer map out some of the other components of the game. This game component framework encourages the game designer to incorporate many essential aspects of games such as rules, events, actions and feedback. However, if the designer is unable to produce a game design, he or she is advised to return to step 5 and select another game core dynamic suited to the mathematics objective and reiterate the process. In this reiteration the designer is advised to select a different pattern in game design or game type. Patterns in game design are suitable for this approach since each pattern provides a list of other related patterns which can be used by the game designer as he or she tries to create a new game. Each pattern contains the name of the pattern, a description of the pattern, the application of the pattern, consequences of game play when the pattern is adopted, and its relation to other patterns.

Figure 2 demonstrates an example of a game designed using the game design technique. It provides a description of how the technique was used and gives a screenshot of the game design. The topic selected for designing the game in this example is Solving Equations. Firstly, a problem is defined and solved showing each step which the learner is expected to understand. Secondly, assuming that the purpose of the game is not to teach how to solve the equation but to reinforce it, a part of the required solution is chosen. Thirdly, the chosen part in this example is to determine which term to transpose next, i.e., which term should be moved to the other side of the equation first.

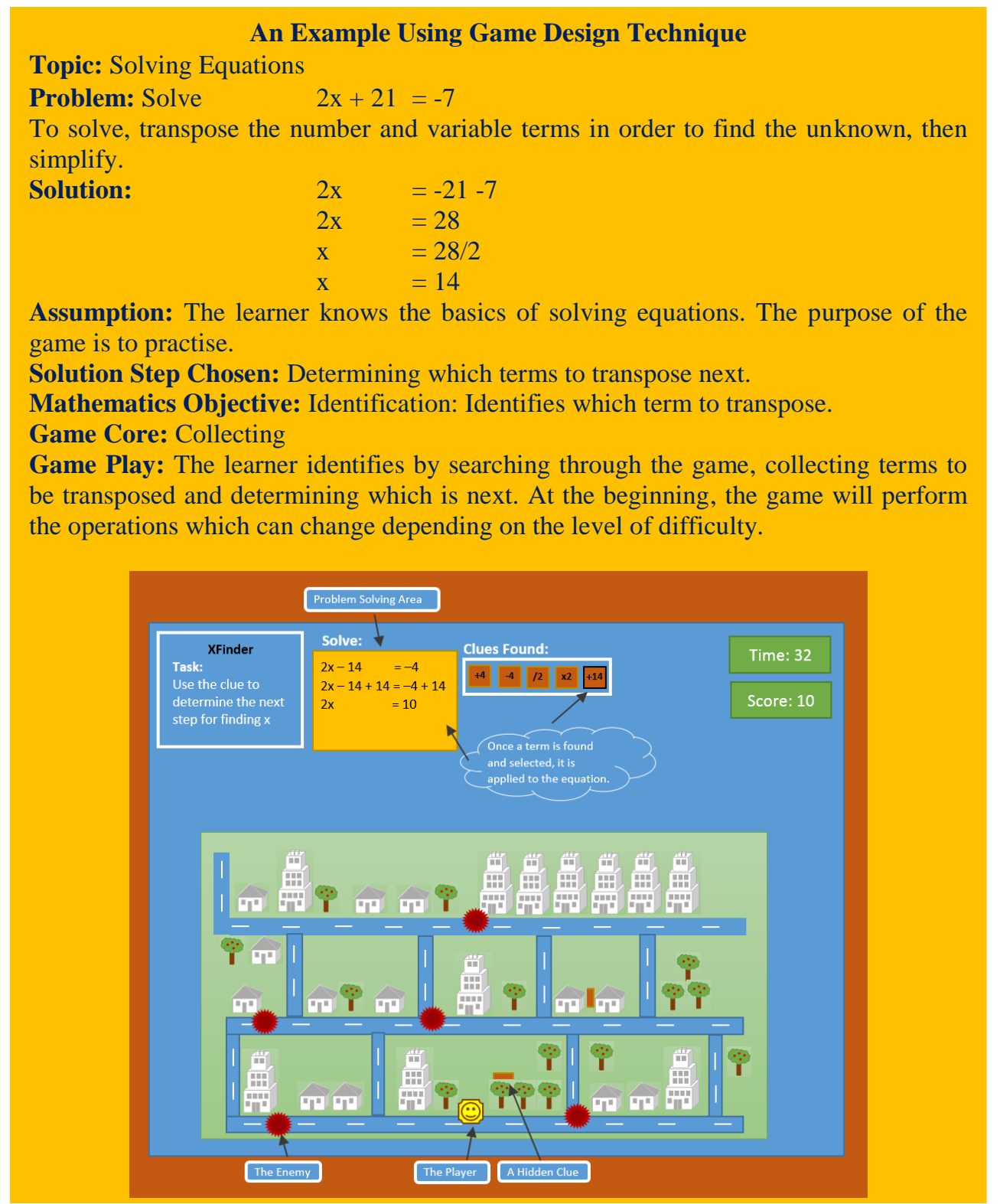

Figure 2. Example of applying the technique to a topic 
Fourthly, it is determined which of the given mathematics objectives (Table 2) best suits the chosen part of the solution. Identification was selected as the objective which suits transposition, because the learner is required to identify which term to transpose next. The game core selected is collecting, where the player has to move around the game world collecting terms and determining which is next to be transposed. Finally, the designer is to elaborate the details of the rest of the game.

The name of the game in Figure 2 is XFinder and the player's main goal is to solve for $x$. The player has to explore a village in search of clues while avoiding the enemy. The clue represents an operation to be applied to the equation in an attempt to solve for $x$. Some operations are useful at a particular point in solving the current equation, while others may not be useful at all. The player needs to determine if an operation is useful and when it should be used. If an operation is not being used at the moment it is stored until the player chooses to use it. If the correct operation is chosen in the correct order the player earns points. Points are lost for the selection of an incorrect operation. Points can be used to request hints if the player is having difficulty. As the clues are collected, the player has to determine which clue provides the first step to solve the problem. When the first step is identified, the operation is performed so that the player can observe. The player then repeats this step until the equation is solved. Scores are provided as the player solves the equation and the game is timed with the intention of using it as a competitive measure.

This game helps the player to recognize the steps in solving an equation. It is designed to help the player by encouraging him with the clues as he decides which operation to apply. The mathematical operation is done automatically but the working is demonstrated so that the player can also learn from the example.

\section{Evaluation of the Technique}

A set of nine amateur game designers was asked to take part in a preliminary study for evaluating our technique. Their experience in game design was varied, from designing as many as one hundred games to as little as three. A significant amount of these games were played by many persons at some point in time. These game designers were given the game design technique which included the guided steps, the mathematics objectives, a detailed breakdown of the mathematics curriculum, the patterns in game design and the game types. A large set of approximately 300 patterns in game designs was provided to each game designer [27]. A list of all the documents supplied to the game designers and an example of a pattern template are provided in the appendix.

Each game designer was asked to attempt designing a mathematics learning game and they were free to choose whether they wanted to use the technique. The game designers were asked to answer a brief questionnaire before the design process in an effort to create a profile of each of them. All the designers ranged from ages 18-35 years and each was at least pursuing a bachelor's degree in Computer Science. There were only two females out of the nine persons. This is aligned with game designer statistics worldwide, as seen in the International Game Developers Association (IGDA) in 2014, which stated that the game designer population consisted of $76 \%$ males [33]. The IGDA survey also showed that the majority of game designers $(60 \%)$ had an undergraduate or post-graduate degree and that $69 \%$ of the game designers were between the ages of 25-39 years. Our group of game designers used in this study fit into the majority profile of a game designer worldwide.

Seven out of the nine game designers were able to successfully complete the game design exercise and since one designer submitted two designs, in total eight games were produced. A questionnaire was used to collect the game designer feedback on the technique and this helped to determine if it was used. Two of the designers never completed the task and did not provide feedback on the technique. All seven game designers were able to complete their game designs and each stated that they all used the game design technique described in the previous section. Each game designer submitted their design notes which served as evidence of his/her use of the technique. These notes showed the topic chosen, the breakdown of the topic, its mapping to an objective, and a choice of a pattern in game design or game type. 
Topic: Number Theory

\section{Eliminator}

Subtopics: Factors, Multiples, Squares

Steps: 1. Identify a number which is a factor, multiple or square of another number

2. Repeat until all numbers are removed

Mathematics Objective: Identification: Identifies a factor, multiple or square.

Pattern in Game Design: Capture - where the end result is the elimination or change of ownership of an actively resisting goal object.

Game Play: Numbers populate a $5 \times 5$ square grid. The player needs to identify numbers which are factors, multiples or squares of another number. A number is eliminated from the grid by dragging and dropping a number (factor, multiple or square) onto another. The objective of the game is to eliminate all number from the grid.
Identifying a factor:

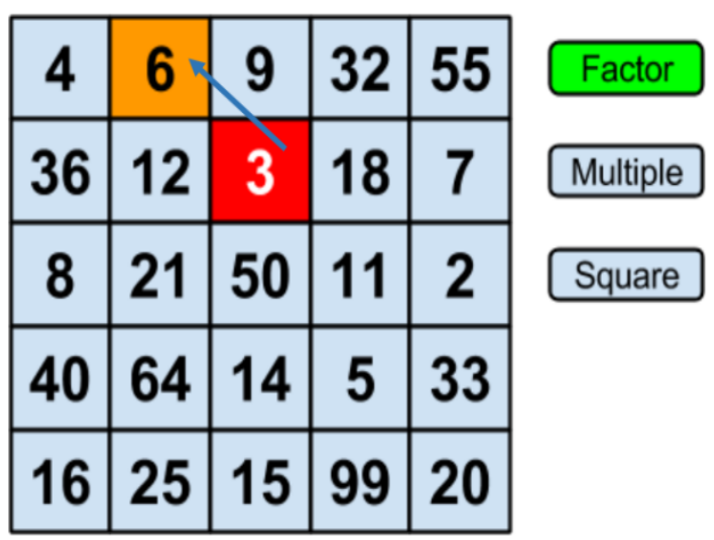

Figure 3. Eliminator Design

\section{Laser War}

Topic: Functions, Relations and Graphs

Subtopic: Equation of a straight line (given 2 points, 1 point and gradient, or gradient of line and relation to another line).

Steps: Formulate equation of a straight line - Equation of a straight line can be found given the following ...

Mathematics Objective: Transposition

Pattern in Games Design: Substitution / Replacement

Game Play: Laser War was designed by game designer number 4 and a screen sketch is shown here. This game teaches the player how to formulate the equation of a straight line. The player has to

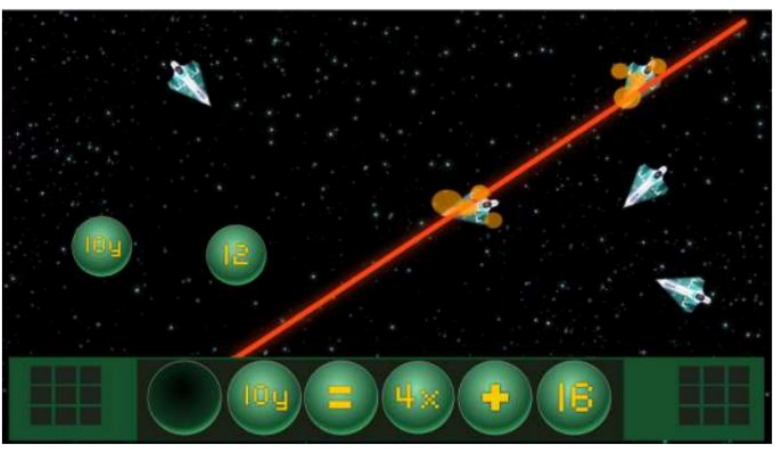
clear all the enemy ships by firing at them. The player is required to complete an equation of a line and a laser is fired when an adequate equation is obtained.

Figure 4. Laser War Design 


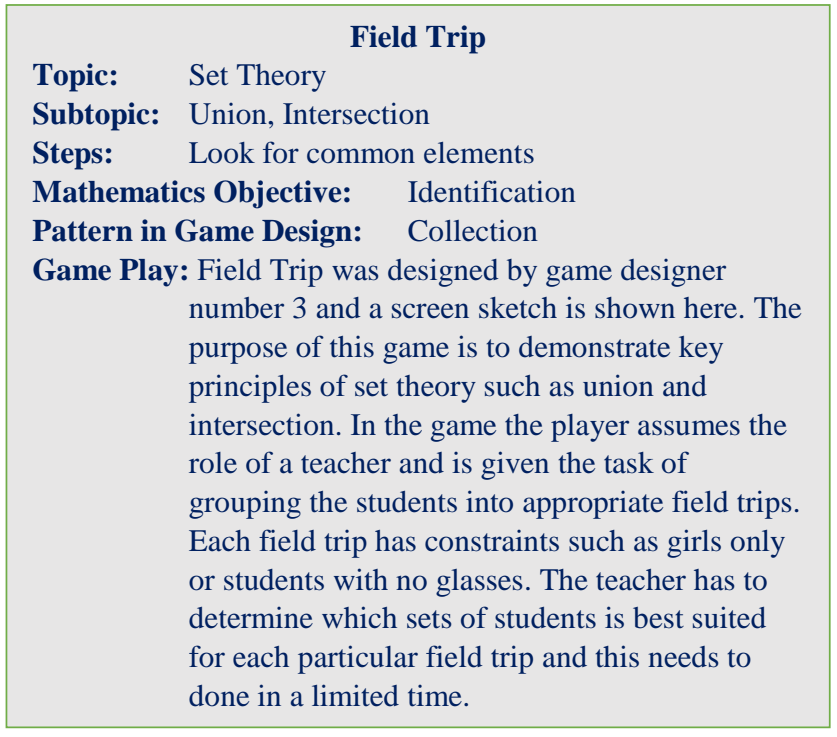

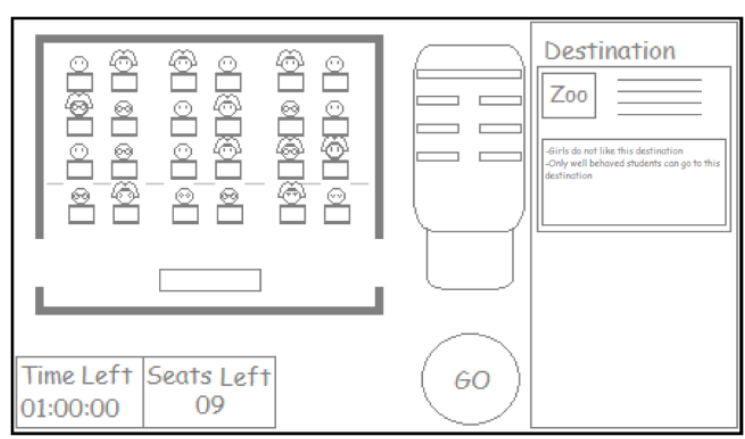

Figure 5. Field Trip Design

Topic: Space Pathfinder
Subtopic: Vectors Addition
Steps: Plot vector 1 and vector 2 then draw the resultant vector to get the answer.
Mathematics Objective: Visual
Pattern in Game Design: Visual and Animated
Game Play: This game was designed by game designer 3 and a screenshot is shown here. This game teaches vectors. The
player has to build a ship to navigate a coordinate system superimposed over space. The ship part options are
provided and different combinations represent different navigational vectors. The ship has to be built to
navigate around obstacles towards a particular goal.

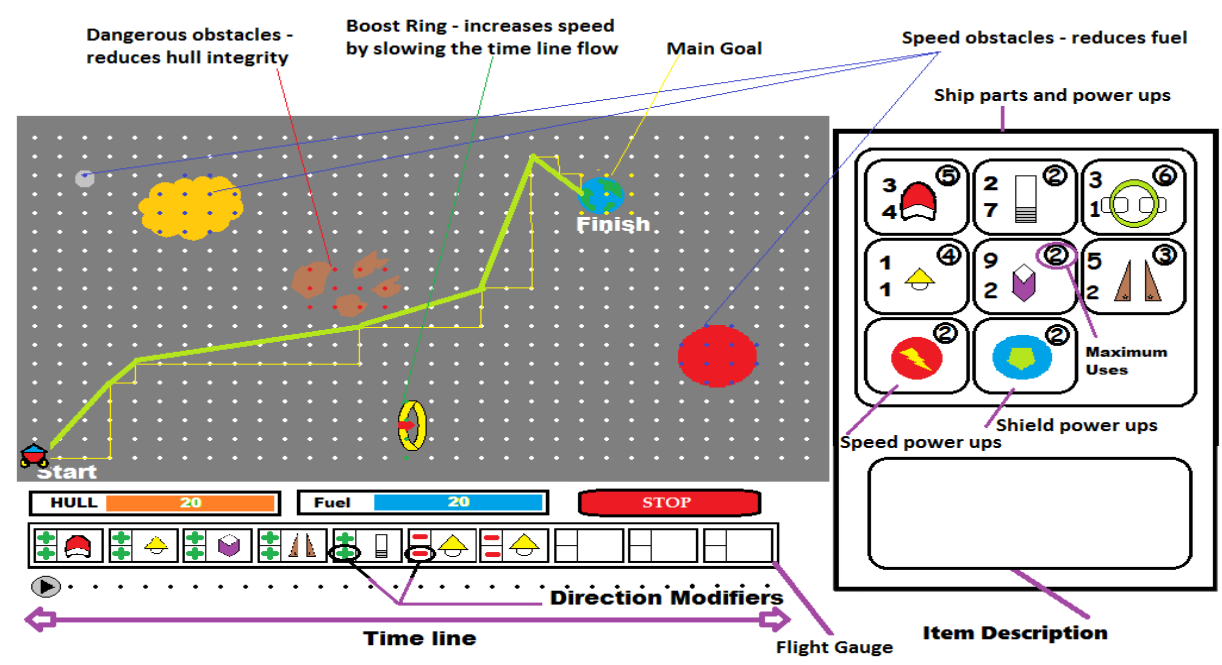

Figure 6. Space Pathfinder Design

Figures 3, 4, 5 and 6 demonstrate four examples of games produced by three game designers. The other games are shown in the appendix. Figure 3 shows the game called Eliminator which is based on Number Theory, and Figure 4 shows Laser War which is based on Equation of a Straight Line. Figure 5 shows a game called Field Trip based on Sets and Figure 6 shows Space Pathfinder which is based on Vectors. Each figure presents the notes showing the steps which each designer took and a screen sketch submitted by the designer. Figures 3, 4, 5 and 6, for example, show that the designers selected the topic, selected a 
subtopic, outlined the steps for solving a typical problem involving this subtopic, chose a suitable mathematics objective, determined a matching pattern in game design and was able to derive a game idea from this. This information presents evidence that the game designer closely followed the technique and was able to successfully design a game.

Six out of the seven game designers gave a score of either 4 or 5 out of 5 showing how useful they thought the technique was. Six out of seven game designers gave at least 3 out of 5 indicating how much easier it was to design the game using the technique. Six out of seven designers gave at least a 3 out of 5 indicating to what degree they thought they were able to design the game more quickly because of the technique. Six out of seven game designers stated that they would use this technique again for designing mathematics learning games. All seven designers stated that they would recommend this technique to other game designers.

Table 3 gives some of the actual comments of the game designers after using the technique. The remaining comments can be seen in the appendix. All seven game designers stated that they used the technique. Only one game designer gave low scores when asked if the technique was useful. A deeper look at this designer's responses revealed that he preferred to work on his own and that guidelines and templates narrowed his thoughts. But this designer thought he would still recommend it to others because it may be useful to those who work best with guidelines or guided techniques. He stated that, in his opinion, the use of the technique was dependent upon the designer's preferences. Other comments from the game designers are as follows: the technique helped to narrow the scope, improve the overall game design, was useful for rapid prototyping, it helped them to define the game mechanics better, provided game ideas and the patterns in game design aspect helped narrow the focus of the game design. These comments highlight that all the game designers found the technique to be beneficial as it helped them to focus on the purpose. It can also be seen that this technique did not stifle their creativity and each designer was able to successfully produce a game design.

Table 3. Detailed comments from the game designers

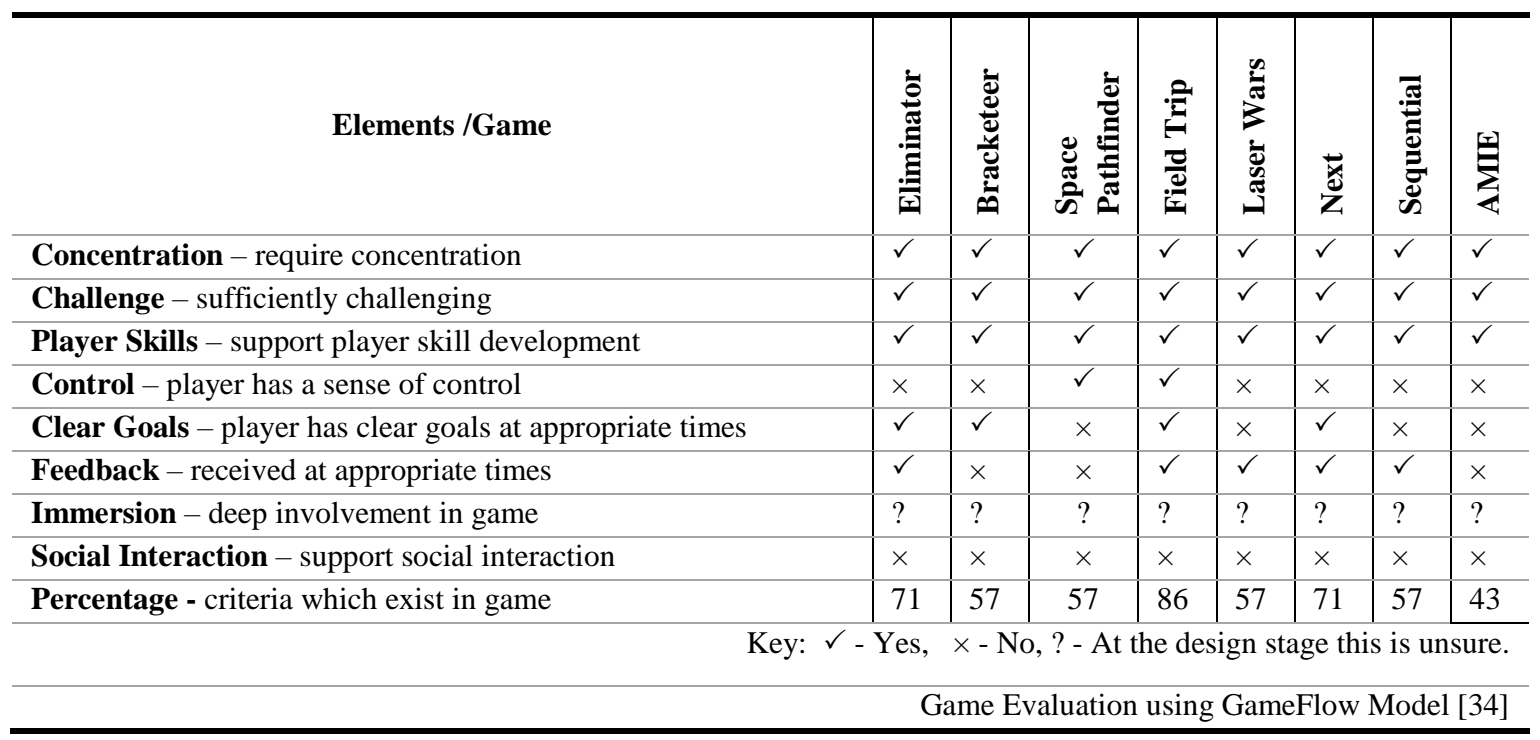


Table 4. Evaluation of the game designs using GameFlow Model.

\begin{tabular}{|c|c|c|c|c|c|c|c|c|}
\hline Elements /Game & 宦 & 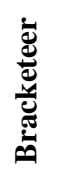 & 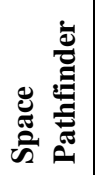 & 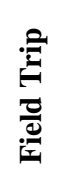 & 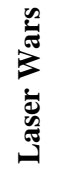 & $\vec{z}$ & 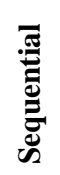 & $\sum_{2}$ \\
\hline Concentration - require concentration & $\checkmark$ & $\checkmark$ & $\checkmark$ & $\checkmark$ & $\checkmark$ & $\checkmark$ & $\checkmark$ & $\checkmark$ \\
\hline Challenge - sufficiently challenging & $\checkmark$ & $\checkmark$ & $\checkmark$ & $\checkmark$ & $\checkmark$ & $\checkmark$ & $\checkmark$ & $\checkmark$ \\
\hline Player Skills - support player skill development & $\checkmark$ & $\checkmark$ & $\checkmark$ & $\checkmark$ & $\checkmark$ & $\checkmark$ & $\checkmark$ & $\checkmark$ \\
\hline Control - player has a sense of control & $x$ & $x$ & $\checkmark$ & $\checkmark$ & $x$ & $x$ & $x$ & $x$ \\
\hline Clear Goals - player has clear goals at appropriate times & $\checkmark$ & $\checkmark$ & $x$ & $\checkmark$ & $x$ & $\checkmark$ & $x$ & $\times$ \\
\hline Feedback - received at appropriate times & $\checkmark$ & $x$ & $x$ & $\checkmark$ & $\checkmark$ & $\checkmark$ & $\checkmark$ & $x$ \\
\hline Immersion - deep involvement in game & $?$ & $?$ & $?$ & $?$ & $?$ & $?$ & $?$ & $?$ \\
\hline Social Interaction - support social interaction & $x$ & $x$ & $x$ & $x$ & $x$ & $x$ & $x$ & $x$ \\
\hline Percentage - criteria which exist in game & 71 & 57 & 57 & 86 & 57 & 71 & 57 & 43 \\
\hline
\end{tabular}

Game Evaluation using GameFlow Model [34]

Table 4 presents the results after comparing each game design from the evaluation to a model of enjoyment in games specified by Sweetser and Wyeth [34]. Sweetser and Wyeth have drawn together various heuristics for designing, evaluating and understanding player enjoyment of games into one concise model. This model is called GameFlow and consists of eight elements for achieving enjoyment. These elements are concentration, challenge, player skill, control, clear goals, feedback, immersion and social interaction. Concentration refers to that fact that the game should provide stimuli, grab and maintain the player's attention and have a high workload requiring concentration. Challenge refers to the fact that the game should match the player's skill, provide different levels of challenge which increase as the player progresses. Player skills refer to the fact that the game should support the player's skill development by being fun, rewarding and easy to use. Control means that the player should feel a sense of control over his/her actions in the game through interactions and movements. Clear goals refer to the point that the game should provide the player with clear goals. Feedback refers to the player receiving appropriate feedback at the right time. Immersion is where the player feels deep effortless involvement in the game. In our research, since we are evaluating game designs and not the actual games, the immersion element will not be used in the evaluation. Social interaction means that the game should support and create opportunity for social interactions. Sweetser and Wyeth have shown that this model provides a deeper understanding of enjoyment in games and it helps to identify strengths and weaknesses as an evaluation tool. Although it is used for reviewing completed games, in our research we use it as an early indicator of enjoyment by applying it to the game designs.

Table 4 shows that at the design stage, seven out of the eight games consist of at least $57 \%$ of the game elements suggested by the GameFlow model. Three of these contained over 70\% of the elements. Given that these are only game designs, a measure of seven out of eight is considered a good evaluation of the games created using the game design technique. Additionally, this can be improved with the development of the actual game. When the game is developed, other features may be included such as feedback, social interaction, and player control. Details of the other games from the evaluation are given in the appendix.

\section{Contribution and Limitations}

In this paper, we presented a technique for guiding the game designer through the mathematics learning game design process with a specific focus on mapping mathematics content to game design. This technique is based on four significant influencing factors. It is based on well researched instructional design and mathematics pedagogy, game categorization, the mathematics curriculum and past research experience in learning mathematics with games. It guides the designer through designing a game which incorporates the mathematics content directly into the game play. It uses common game design ideas which have proven to be successful, encouraging game designers to integrate such ideas into their games.

We have identified a set of game design principles which can benefit other researchers in this area. Firstly, when designing learning games, the content should be broken down into subtopics. This provides 
the advantage of it being easier to design a game with a small topic and also easier for the player to understand when playing. Secondly, it is beneficial by encouraging the designer to focus on the mathematics content while designing the game which ensures that the game play directly involves the mathematics content. Lastly, the game designer should ensure that the game incorporates authentic game characteristics such as rewards, chance, competition, strategy and constraints. The designer should create the game in such a way that it is seen as a game by the players and not just a learning activity. We propose that these key game design principles can greatly improve the success of mathematics learning games.

The technique presented in this paper has several advantages over other approaches to game designs.

- The technique is more specific to the domain of mathematics than other techniques encountered in the literature. It gives guidelines for incorporating mathematics as a direct part of the game play.

- The technique is based on several influencing factors affecting the learning and games, such as the mathematics curriculum, successful game design, and well researched learning theories and mathematics pedagogy.

- The technique is a guide for designing games whereas other tools mainly focus on improving the game development process.

- Becker and Parker [15] pointed out that it is common to find guidelines for designing learning games which assume that the user is already familiar with game design. The technique presented in this paper does not assume that the user is familiar with game design or the mathematics content. However, it is also flexible, being applicable to an amateur game designer or professional.

- Becker and Parker [15] implied that game designers tend to focus on the game and insert the content after game design is completed, whereas the instructional designers do the opposite. This results in the game and the content not being well integrated with each other. The technique presented encourages the designer to get involved in the game and the content, deeply integrating each one with the other.

- The technique makes use of proven successful patterns in game design. The incorporation of these patterns in game design increases the possibility that the game can contain appealing and compelling factors, such as those present in other successful games.

Many researchers [35] have pointed out that creating and innovating comes from building on top of the work of others and seldom does it emerge out of absolutely nothing. Researchers have even recognized that most game designs are not totally new but it is built based on knowledge of previous games. This is an essential concept used in the technique presented. This technique attempts to inspire the game designer by reusing good ideas and consequently incorporating the advantages gained. Reusing good game ideas increases the chance that the game will contain compelling and appealing qualities. Furthermore, reuse can result in less effort and time spent on the game design process. Reuse can make the game design process easier as these successful ideas can provide inspiration, making the creation of new ideas easier. Conversely, the technique presented in this paper is not without limitations. The evaluation conducted involved amateur game designers, implying that they may not have enough experience to comment sufficiently on the technique. We can draw the conclusion that they found it useful. However, more evaluations are necessary in order to get feedback from more seasoned game designers. The small sample size is also a limitation to the study; however, with sufficient time this can be improved as it will allow for the mobilization of more game designers to try out the technique. Another limitation to this approach is that this technique may not be suitable for all game designers' personal preferences for designing games. However, the technique is intended for game designers who want a structured approach or may be new to designing games. Additionally, the technique provides room for designer freedom. The use of the patterns in game design increases the probability that the game would incorporate successful game features resulting in a successful game. However, there is no guarantee that the game will be successful. Another limitation is that the technique only tackles one portion of game design, which is mapping the mathematics to the game idea but there are other obstacles such as ensuring that the game is recognized as a success by its target group. Nevertheless, this particular aspect of game design was chosen because it is a significantly difficult process in mathematics learning game design. Despite these limitations we suggest that this technique can be a useful tool for game designers of mathematics learning games, and with future refinement and improvement can contribute greatly to the field of mathematics educational game design. 
In this paper, we presented a technique for mapping mathematics content to game design in an effort to improve the creation of mathematics learning games. The design of mathematics learning games can be a tedious and time consuming process where these efforts can often result in the creation of unsuccessful games. In this paper, we have presented a technique which helps the game designer to smoothly map mathematics content to game play when designing mathematics learning games. This technique was developed based on several factors which are believed to strongly influence game design and learning mathematics. The incorporation of mathematics pedagogy and instructional design increases the possibility that learning will occur. The reuse of patterns in game designs and game types can provide a wide range inspiration for mapping the mathematics content to a game idea. This technique helps the designer focus his efforts on the content, the game core and the suitable mapping of the two. The paper has shown that a set of amateur game designers was able to use the technique to produce a collection of designs for mathematics learning games and also provide informative positive feedback based on this work. They also found the technique to be useful. More evaluations are necessary in an effort to acquire feedback from a wider range of game designers. This feedback can be used to refine the technique, improving its use. Next, a comparison of the games produced by the technique with games produced not using it would be beneficial. It would also be interesting to look at the game play experience of these games when developed. In the future, the technique will be enhanced, taking into consideration other significant aspects of game design and learning mathematics such as other learning theories and game evaluation models.

\section{References}

[1] Tüzün, H., Yilmaz-Soylu, M., Karakuş, T., İnal, Y., Kizilkaya, G., The effects of computer games on primary school students' achievement and motivation in geography learning. Computers \& Education, Vol. 52, Nr. 1, pp. 68-77, 2009. http://dx.doi.org/10.1016/j.compedu.2008.06.008

[2] Prensky, M., Digital natives, digital immigrants part 1. On the horizon, Vol. 9, Nr. 5, pp. 1-6, 2001. http://dx.doi.org/10.1108/10748120110424816

[3] Garris, R., Ahlers, R., Driskell, J. E., Games, motivation, and learning: A research and practice model. Simulation and Gaming, Vol. 33, Nr. 4, pp. 441-467, 2002. http://dx.doi.org/10.1177/1046878102238607

[4] Connolly, T. M., Stansfield, M., Hainey, T., An application of games-based learning within software engineering. British Journal of Educational Technology, Vol. 38, Nr. 3, pp. 416-428, 2007. http://dx.doi.org/10.1111/j.1467-8535.2007.00706.x

[5] Gee, J. P., What video games have to teach us about learning and literacy? ACM Computers in Entertainment (CIE), Vol. 1, Nr. 1, pp. 20-20, 2003. http://dx.doi.org/10.1145/950566.950595

[6] Carr, J., Does Math Achievement h'APP'en when iPads and Game-Based Learning are Incorporated into Fifth-Grade Mathematics Instruction? Journal of Information Technology Education: Research, Vol. 11 Nr. 1, pp. 269-286, 2012.

[7] Tobias, S., Fletcher, J. D., What do we know about the learning effectiveness of computer games. In AERA 2008 Conference, New York, 24-28 March, 2008.

[8] Papastergiou, M., Exploring the potential of computer and video games for health and physical education: A literature review. Computers \& Education, Vol. 53, Nr. 3, pp. 603-622, 2009. http://dx.doi.org/10.1016/j.compedu.2009.04.001

[9] Koster, R., "Theory of fun for game design". O'Reilly Media, Inc.: Sebastopol, CA, 2013.

[10] Salingaros, N. A., Architecture, patterns, and mathematics. Nexus Network Journal, Vol. 1, Nr. 1-2, pp. 75-86, 1999. http://dx.doi.org/10.1007/s00004-998-0006-0

[11] Ke, F., Grabowski, B., Game playing for maths learning: cooperative or not? British Journal of Educational Technology, Vol. 38, Nr. 2, pp. 249-259, 2007. http://dx.doi.org/10.1111/j.14678535.2006.00593.x

[12] Rosas, R., Nussbaum, M., Cumsille, P., Marianov, V., Correa, M., Flores, P., Grau, V., et al, Beyond Nintendo: design and assessment of educational video games for first and second grade students. Journal of Computers \& Education, Vol. 40, Nr. 1, pp. 71-94, 2003. http://dx.doi.org/10.1016/S0360-1315(02)00099-4

[13] Klawe, M., "When does the use of computer games and other interactive multimedia software help students learn mathematics?" Proceedings of NCTM (National Council of Teachers in 
Mathematics) Standards 2000 Technology Conference. Arlington, VA, USA. Retrieved April 2, 2015 from http://mathforum.org/technology/papers/papers/klawe.html, 5-6 June 1998.

[14] Asplin, P., Frid, S., Sparrow, L., "Game playing to develop mental computation: A case study." In Grootenboer, P., Zevenbergen, R. and Chinnappan, M., (Eds.), Identities, cultures, and learning spaces, Proceedings of the 29th Conference of the Mathematics Education Research Group of Australasia. Canberra, Australia, pp. 46-53, 2006.

[15] Becker, K., Parker, J. R., "The Guide to Computer Simulations and Games”. John Wiley \& Sons: IN, USA, 2011.

[16] Rogers, S., “Level Up!: The Guide to Great Video Game Design”. John Wiley \& Sons: New Jersey, USA, 2010.

[17] Schell, J., “The Art of Game Design: A book of lenses.” CRC Press, Taylor \& Francis Group: Boca Raton, FL, 2014. http://dx.doi.org/10.1201/b17723

[18] Salen, K., Zimmerman, E., "Rules of play: Game design fundamentals". MIT press: Massachusetts, USA, 2004.

[19] Torrente, J., Moreno-Ger, P., Fernández-Manjón, B., Sierra, J. L., "Instructor-oriented authoring tools for educational videogames." Proceedings of Advanced Learning Technologies, ICALT'08. Eighth IEEE International Conference, Santander, Spain, pp. 516-518, 1-5 July 2008. http://dx.doi.org/10.1109/icalt.2008.177

[20] Abdullah, N. A., Kamaruddin, R.H.R.A., Razak, Z., Yusoff, Z. M., “A Toolkit Design Framework for Authoring Multimedia Game-Oriented Educational Content." Proceedings of Advanced Learning Technologies, ICALT'08. Eighth IEEE International Conference. Santander, Spain, pp.144-145, 1-5 July 2008. http://dx.doi.org/10.1109/icalt.2008.216

[21] Gómez-Martín, M. A., Gómez-Martín, P. P., González-Calero, P. A., "Data Driven Software Architecture for Game-Based Learning Systems", In Taisch, M. and Cassina, J. (Eds.), Proceedings of the $1^{\text {st }}$ Learning with Games Conference, Sophia Antipolis, France, pp. 229 236. 24-26 September, 2007.

[22]Fanning, E., Game Mods: Customizable Learning in a K16 setting. International Journal of Information and Communication Technology Education (IJICTE), Vol. 2, Nr. 4, pp. 15-23, 2006. http://dx.doi.org/10.4018/jicte.2006100102

[23] Prensky, M., Digital game-based learning. Computers in Entertainment (CIE), Vol. 1, Nr. 1, pp. 21, 2003. http://dx.doi.org/10.1145/950566.950596

[24] Tondeur, J., Van Braak, J., Valcke, M., Curricula and the use of ICT in education: Two worlds apart? British Journal of Educational Technology, Vol. 38, Nr. 6, pp. 962-976, 2007. http://dx.doi.org/10.1111/j.1467-8535.2006.00680.x

[25] Moreno-Ger, P., Burgos, D., Martínez-Ortiz, I., Sierra, J. L., Fernández-Manjón, B., Educational game design for online education. Computers in Human Behavior, Vol. 24, Nr. 6, pp. 25302540, 2008. http://dx.doi.org/10.1016/j.chb.2008.03.012

[26] Arnab, S., Lim, T., Carvalho, M. B., Bellotti, F., de Freitas, S., Louchart, S., Suttie, N., Berta, R., De Gloria, A., "Mapping learning and game mechanics for serious games analysis," British Journal of Eucational Technology, Vol. 46, Nr. 2, pp. 391-411, 2015. http://dx.doi.org/10.1111/bjet.12113

[27]Björk, S., Holopainen, J., "Patterns in Game Designs", Charles River Media Game Development: Ma, USA, 2004.

[28] Becker, K., "How Are Games Educational? Learning Theories Embodied in Games". In Proceedings of 2nd International DIGRA Conference, "Changing Views: Worlds in Play", Vancouva, BC, 16-20 June, 2005.

[29] Gee, J. P., Good video games and good learning. In Phi Kappa Phi Forum, The Honor Society of Phi Kappa Phi. Vol. 85, Nr. 2, pp. 33-37, 2005.

[30] Anthony, G., Walshaw, M., Effective pedagogy in mathematics, Brophy, J. (Ed.), Iterative Best Evidence Synthesis (BES) Program, Wellington, New Zealand: Ministry of Education, 2007. http://unesco.atlasproject.eu/unesco/file/7003a59d-3f2f-4e79-9ddc-5835d113b828/c8c7fe00c770-11e1-9b210800200c9a66/183624e.pdfhttp://www.ibe.unesco.org/fileadmin/user_upload/Publications/Educ ational_Practices/EdPractices_19.pdf

[31] Kalloo, V., Mohan, P., An Investigation Into Mobile Learning for High School Mathematics, International Journal of Mobile and Blended Learning, Vol. 3, Nr. 3, pp. 60-77, July-September, 2011.

[32] Brathwaite, B., Schreiber, I., "Challenges for game designers". Charles River Media: Boston, MA, 2009. 
[33] "Developer Satisfaction Survey 2014 - Summary Report, International Game Developers Association", https:/c.ymcdn.com/sites/www.igda.org/resource/collection/9215B88F-2AA34471-B44D-B5D58FF25DC7/IGDA_DSS_2014-Summary_Report.pdf.

[34] Sweetser, P., Wyeth, P., GameFlow: a model for evaluating player enjoyment in games. Computers in Entertainment (CIE), Vol. 3, Nr. 3, pp. 3-3, 2005. http://dx.doi.org/10.1145/1077246.1077253

[35] Koster, R., "Practical Creativity", Lecture at Game Developers Conference Next featuring App Developers Conference, Los Angeles, CA. http://www.raphkoster.com/gaming2/presentations/practical-creativity/, 3-4 November, 2014. 


\section{Appendix}

Table A1. Games designed in the evaluation

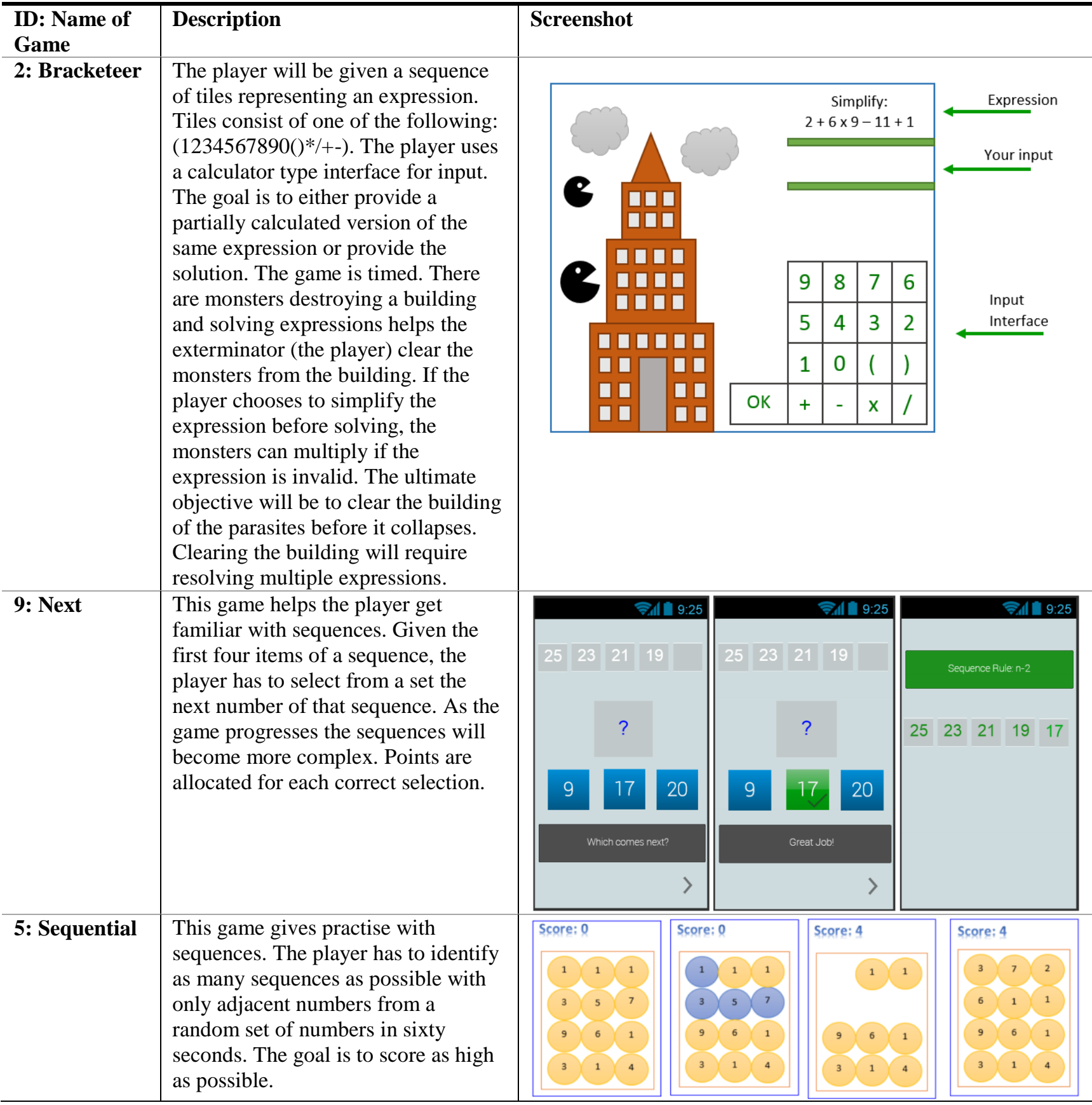




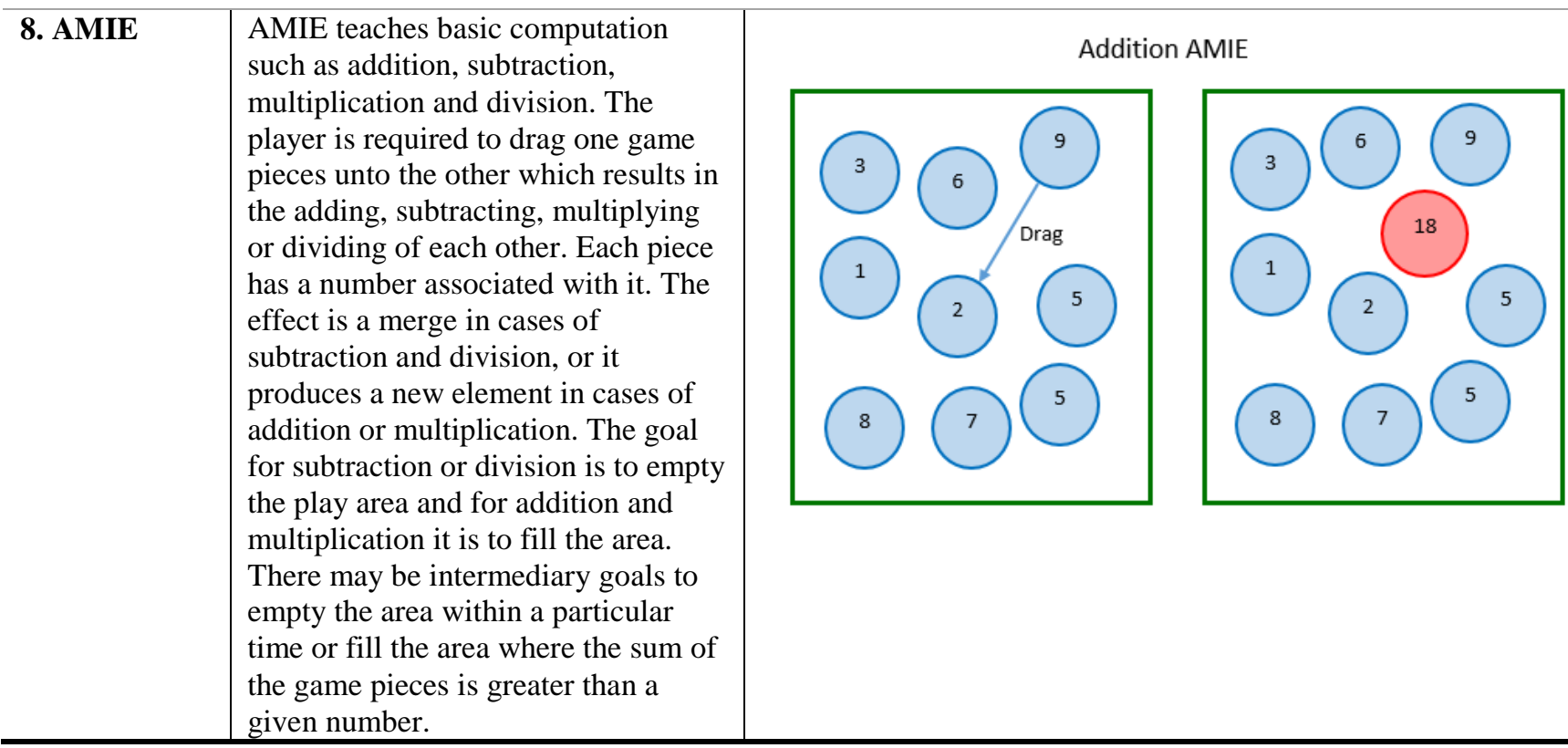

Table A2. Patterns in Game Design Template.

\section{Pattern in Game Design Template Example [27]}

\begin{tabular}{l|l}
\hline Name: & Last Man Standing \\
\hline Description: & $\begin{array}{l}\text { This pattern represents the goal of being the last survivor. Players compete against } \\
\text { each other in gameplay where the players are eliminated one after the other. }\end{array}$ \\
\hline $\begin{array}{l}\text { Using the } \\
\text { patterns: }\end{array}$ & $\begin{array}{l}\text { Creating a game with this pattern requires direct elimination goals towards other } \\
\text { players or overcome goals where the penalty of losing is elimination. } \\
\text { This pattern creates conflict between the players and provides competition for all } \\
\text { players. }\end{array}$ \\
\hline $\begin{array}{l}\text { Relations to } \\
\text { other patterns: }\end{array}$ & $\begin{array}{l}\text { Instantiates the following patterns: Conflict, Competition, Overcome, Collection, } \\
\text { Tournaments. } \\
\text { Instantiated by the following patterns: Eliminate. } \\
\text { Modulated by the following patterns: Lives, Limited Resources, Player Elimination. } \\
\text { Conflict with the following patterns: None. }\end{array}$ \\
\hline
\end{tabular}


Table A3. Game designer comments after using the game design technique.

\begin{tabular}{|c|c|c|c|}
\hline $\begin{array}{l}\text { State the } \\
\text { name of } \\
\text { your } \\
\text { game: }\end{array}$ & $\begin{array}{c}\text { Please state any } \\
\text { suggestion(s) you have to } \\
\text { improve the } \\
\text { methodology }\end{array}$ & $\begin{array}{c}\text { Please state the reason(s) for } \\
\text { using it again. }\end{array}$ & $\begin{array}{l}\text { Please state the reason(s) for } \\
\text { recommending it to others. }\end{array}$ \\
\hline Eliminator & & $\begin{array}{l}\text { It helps to narrow the scope which } \\
\text { leads to a tighter game design } \\
\text { overall. }\end{array}$ & $\begin{array}{l}\text { It can be useful especially for rapid } \\
\text { prototyping. }\end{array}$ \\
\hline Bracketeer & & $\begin{array}{c}\text { I tend to come up with better ideas } \\
\text { when I stay away from templates } \\
\text { and guidelines. they usually narrow } \\
\text { my thoughts too much }\end{array}$ & $\begin{array}{l}\text { If the designer is more methodical } \\
\text { about their creative process then } \\
\text { yes }\end{array}$ \\
\hline $\begin{array}{c}\text { Space } \\
\text { Pathfinder }\end{array}$ & $\begin{array}{l}\text { If possible more topic } \\
\text { objectives to help with } \\
\text { defining games. }\end{array}$ & $\begin{array}{l}\text { The methodology added structure } \\
\text { to coming up with a game. }\end{array}$ & $\begin{array}{l}\text { Helps in defining a game in more } \\
\quad \text { detail. } \\
\text { Provides mechanics and ideas } \\
\text { which can be included in the game. }\end{array}$ \\
\hline $\begin{array}{l}\text { Laser } \\
\text { Wars }\end{array}$ & $\begin{array}{l}\text { Allow use of multiple } \\
\text { patterns in game design. } \\
\text { Allow a flow chart system } \\
\text { that can encapsulate the } \\
\text { designs of larger and more } \\
\text { complex games. }\end{array}$ & $\begin{array}{l}\text { I believe the design pattern system } \\
\text { helps focus on various aspects of } \\
\text { the game mechanics, and helps } \\
\text { narrow down the design of the } \\
\text { gameplay. It provides a structure, } \\
\text { of which creativity can flourish } \\
\text { around. }\end{array}$ & $\begin{array}{l}\text { I would recommend this } \\
\text { methodology to other game } \\
\text { designers due to the fact that it } \\
\text { provides a structure which they can } \\
\text { then inject their own creativity } \\
\text { into. }\end{array}$ \\
\hline \multicolumn{4}{|l|}{ Next } \\
\hline Sequential & & $\begin{array}{l}\text { My response above is more of a } \\
\text { maybe, this is just because it is } \\
\text { easier to design a game and then } \\
\text { see where it fits, than to design one } \\
\text { to fit somewhere specifically }\end{array}$ & $\begin{array}{l}\text { It was definitely an interesting } \\
\text { approach and somewhat forced and } \\
\text { focused my thought process. I can } \\
\text { see someone benefitting from the } \\
\text { method especially when the } \\
\text { developer has a particular goal } \\
\text { intended for the user, such as that } \\
\text { of an educational math based } \\
\text { game. }\end{array}$ \\
\hline AMIE & Not at the time & $\begin{array}{l}\text { The methodology makes it easy to } \\
\text { develop a math game. } \\
\text { I particularly liked the formulaic } \\
\text { approach to a largely creative and } \\
\text { sometimes unstructured process. } \\
\text { I liked that it helps choose a genre } \\
\text { suitable to a particular subject area, } \\
\text { this in my opinion is the hardest } \\
\text { part of designing educational } \\
\text { games. }\end{array}$ & $\begin{array}{l}\text { Good place to start the process of } \\
\text { creating an educational game. Can } \\
\text { take the guesswork out of choosing } \\
\text { a genre for the game. }\end{array}$ \\
\hline
\end{tabular}

Table A4. A list and explanation of the documents given to game designer.

\begin{tabular}{c|l}
\hline $\begin{array}{c}\text { Documents given to } \\
\text { Game Designer }\end{array}$ & \multicolumn{1}{c}{ Explanation of the documents } \\
\hline The Technique & $\begin{array}{l}\text { This explains the technique which is intended as a guide for designing a } \\
\text { mathematics game. }\end{array}$ \\
\hline $\begin{array}{c}\text { Patterns in Game } \\
\text { Design and Game } \\
\text { Types }\end{array}$ & $\begin{array}{l}\text { A list of the patterns in game design by Bjork and Holopainen and game types. } \\
\text { This is to be used as part of the technique as a suggestion for ideas; your idea is } \\
\text { not limited to these. }\end{array}$ \\
\hline Mathematics & The detailed list of the mathematics topics and objectives which you can choose \\
\hline
\end{tabular}




\begin{tabular}{c|l}
\hline Curriculum & from. \\
An Example & $\begin{array}{l}\text { An example of using the method and the component framework suggested by } \\
\text { Bjork and Holopainen, to complete the game. }\end{array}$ \\
\hline Patterns Explained & Explains the game patterns by Bjork and Holopainen. \\
\hline
\end{tabular}

